\title{
A Method to Determine the Margins of High Sea Ice Concentration Using AMSR-E Passive Microwave Imagery
}

\author{
Shugang Zhang1,2, Shixuan Liu'1,2, Shuwei Zhang1,2, Shizhe Chen",2 \\ ${ }^{1}$ Institute of Oceanographic Instrumentation, Shandong Academy of Sciences, Qingdao, China \\ ${ }^{2}$ Shandong Provincial Key Laboratory of Ocean Environmental Monitoring Technology, Qingdao, China \\ Email: zhangshugang6@163.com
}

How to cite this paper: Zhang, S.G., Liu, S.X., Zhang, S.W. and Chen, S.Z. (2017) A Method to Determine the Margins of High Sea Ice Concentration Using AMSR-E Passive Microwave Imagery. Journal of Geoscience and Environment Protection, 5, 15-25.

https://doi.org/10.4236/gep.2017.56003

Received: January 13, 2017

Accepted: June 9, 2017

Published: June 12, 2017

\begin{abstract}
The margin of the sea ice with high sea ice concentration is a principal feature in microwave image and a hotspot in image recognition. A method for determining the margins is developed using the feature of dual-polarized brightness temperatures at $36.5 \mathrm{GHz}$ and a new parameter (contrast ratio) is used in this paper. For the microwaves, the ratio of the horizontal-polarized emissivity to the vertical-polarized emissivity is approximately equal to the ratio between horizontal-polarized and vertical-polarized brightness temperatures of sea surface, which called as the dual-polarized emissivity ratio in this study. It is found that the dual-polarized emissivity ratio of sea ice with nearly $100 \%$ sea ice concentration in Arctic at $36.5 \mathrm{GHz}$ band has a value ranged between 0.92 and 0.96 , as shown by satellite-observed data in figure of horizontal-polarized brightness temperature versus vertical-polarized brightness temperature. From open water to sea ice covered area, the contrast-ratio can show the changing features of the dual-polarized brightness temperature at $36.5 \mathrm{GHz}$. The contrast ratio rapidly changes at the ice margins and its gradient appears an extreme value when the ratio changes around 0.92. This extreme value is examined by the ice concentration calculated by the MODIS data. And the results indicate that the threshold ratio coincides with the contour line of $96 \%$ sea ice concentration. So the parameter of contrast ratio could be used to determine the position of margins in microwave image.
\end{abstract}

\section{Keywords}

Arctic Sea Ice, Ice Margin, AMSR-E, $36.5 \mathrm{GHz}$

\section{Introduction}

Arctic sea ice is one of the most important parameters in the global climate sys- 
tem, and is experiencing profound declines in areal extent, thickness, and ice age [1] [2] [3]. This rapid change in sea ice forms part of a series of Arctic climate transitions, which include shifts in the atmospheric circulation with concomitant changes in air temperature and an increase in melt-water storage in the upper Arctic Ocean [4] [5] [6] [7]. The IPCC's fifth Assessment Report suggests that Arctic sea ice will disappear during summer of 2100 [8]. Clearly, model results overestimate the change of sea ice because some physical processes and parameters are not fully know for accurately predicting the information of ice pack [9]. Therefore, knowledge of any information of the Arctic ice is of very importance for modeling and predicting the global climate.

The position and motion of the ice margins are important parameters for sea ice dynamics, thermodynamics and climate research [10]. Sea ice concentration is a useful parameter to define the ice margins. For example, the generally high concentration of ice margins in the Arctic Basin, the Beaufort Sea and Chukchi Sea can be taken as $96 \%$ [11]. The marginal ice zone (MIZ) is a mixed region of sea ice and seawater and compressed ice region have generally high concentration. These two regions have different effects on climate and sea water. There is no apparent boundary between MIZ and compressed ice region, because sea ice concentration generally exhibited a gradual change in these regions. The margins of compressed ice region (ice margins) were investigated by using passive microwave imagery in this paper. The margin will to be determined by using a new method depending on the features of remote sensing data.

Satellite remote sensing of the polar ice caps is one of the most important tools to determine the ice margins. Optical sensors can provide high resolution image, however it is only useful for sea ice monitoring under clear sky conditions and during the day [12]. Passive microwave sensors are alternative choice for observing sea ice since microwaves can penetrate heavy clouds and precipitations [13]. Therefore a large number of microwave radiation data are used in the study of sea ice concentration, sea ice extent and sea ice types and so on [3] [14] [15] [16].

The Advanced Microwave Scanning Radiometer-EOS (AMSR-E) sensor on board EOS-Aqua, which was launched by NASA in May 2002, measures microwave radiances at six frequencies, including 6.925, 10.65, 18.7, 23.8, 36.5 and $89.0 \mathrm{GHz}$ at both horizontal and vertical polarizations. It provides a significant improvement in our capability for monitoring the sea ice cover. The Moderate Resolution Imaging Spectroradiometer (MODIS) acquires data in 36 different spectral bands $(0.4-14.4 \mu \mathrm{m})$ and its spatial resolution of the bands ranges from $250 \mathrm{~m}$ to $1 \mathrm{~km}$. Because MODIS images can provide an unambiguous determination of the ice edge, it was acquired to verify the position of sea ice edge [17], accuracy of sea ice concentration [18] and the detection of sea ice leads [19].

In the study of the ice coverage, the brightness temperature, which comes from the open water, from the ice-covered area, or from a mix of both, can be expressed in terms of the relative contribution from each surface type by a linear mixing formulation [13]. In winter, there is a high correlation between the hori- 
zontal-polarized and vertical-polarized brightness temperatures at $36.5 \mathrm{GHz}$ (HV36.5), which were approximately distributed in a line in two-dimensional plot. On the one hand, sea water and melt pond have similarly microwave radiation characteristics [20], so it is impossible to distinguish between melt pond and sea water using brightness temperature. On the other hand, there are little $100 \%$ pixel during summer time. For these two reasons, the HV36.5 data lost its distinct features in the summer. Therefore, HV36.5 data is used only in spring, autumn and winter when sea ice concentration is retrieved.

Although the position of the ice margins is one of principal features in passive microwave imagery, there was no good method for recognition until now. A method to detect ice margins with HV36.5 image is presented here. The method focuses on the detection of the edge, where sea water has weakly affected to the microwave radiation. The used brightness temperature data and proposed method are elaborated in Section 2. At same time, a new parameter to distinguish ice margins in passive microwave image is used. In Section 3, the results are examined and validated.

\section{Methods}

\subsection{AMSR-E Dual-Polarized Brightness Temperature at $36.5 \mathrm{GHz}$}

The basic radiative transfer equation that expresses the brightness temperature $T_{b}$ in terms of surface emission, accounting for atmospheric and other effects is given by [13]

$$
T_{b}=\varepsilon T_{s} e^{(-\tau)}+T_{u}+(1-\varepsilon) T_{d} e^{(-\tau)}+(1-\varepsilon) T_{c} e^{(-2 \tau)}
$$

where the first term is the dominant term that represents radiation received directly from the earth's surface, $T_{s}$ is the physical temperature of the surface, $\varepsilon$ is the surface emissivity, and $\tau$ is the atmospheric opacity. The second term $T_{u}$ represents radiation directly from atmosphere. The third term represents downwelling radiation from the atmosphere reflected by the surface of the earth. The last term is the radiation from outer space which is a negligible additive contribution.

Below $40 \mathrm{GHz}$ only water vapor has weakly absorbing at $22 \mathrm{GHz}$, but atmospheric moisture content at Arctic is very small [11]. So the net effect of the atmospheric temperature is very small and is ignored. The brightness temperature $T_{b}$ could be expressed as a function of the sea ice temperature $T_{i}$ and the water temperature $T_{w}$

$$
T_{b}=\varepsilon_{i} T_{i} C+\varepsilon_{w} T_{w}(1-C)
$$

where $C$ is sea ice concentration, $\varepsilon_{i}$ and $\mathcal{\varepsilon}_{w}$ are sea ice microwave emissivity and sea water microwave emissivity, respectively. Equation (2) is a basic equation in sea ice concentration algorithm, such as ABA, BBA and NASA Team [13]. The National Snow and Ice Data Center (NSIDC) of the USA provides the $12.5 \times$ $12.5 \mathrm{~km}$ gridded AMSR-E brightness temperature and sea ice concentration retrieved using the ABA and NT2 algorithms at the same grid 
(http://nsidc.org/data/amsre). Figure 1(a) shows the horizontal-polarized brightness temperature versus vertical-polarized brightness temperature observed at $36.5 \mathrm{GHz}$ on March 1, 2009. In Figure 1(a), the observed data distributed along the straight line $\mathrm{AD}$ with a slope of 0.94 were corresponding to nearly $100 \%$ ice concentration [16].

When the sea ice concentration equals 1, Equation (2) can be written as

$$
\begin{aligned}
T_{b}(\text { V36.5 }) & =\varepsilon_{i}\left(\text { V36.5) } T_{i}\right. \\
T_{b}(H 36.5) & =\varepsilon_{i}(H 36.5) T_{i} .
\end{aligned}
$$

where H36.5 denotes the horizontal-polarized brightness temperature observed at $36.5 \mathrm{GH}, \mathrm{V} 36.5$ denotes the vertical-polarized brightness temperature observed at $36.5 \mathrm{GHz}$.

From Equation (3b) and Equation (3a), for the sea surface with nearly 100\% ice concentration we have:

$$
T_{b}(H 36.5) / T_{b}(V 36.5)=\left[\varepsilon_{i}(H 36.5) T_{i}\right] /\left[\varepsilon_{i}(V 36.5) T_{i}\right]=\alpha
$$

or

$$
T_{b}(H 36.5)=\left[\varepsilon_{i}(H 36.5) / \varepsilon_{i}(V 36.5)\right] \cdot T_{b}(V 36.5)=\alpha \cdot T_{b}(V 36.5)
$$

where $\alpha$ is the ratio of the horizontal-polarized emissivity to the vertical-polarized emissivity. For simplicity, we call $\alpha$ as the dual-polarized emissivity ratio in this study.

From Equation (4), we know that the dual-polarized emissivity ratio $\alpha$ is approximately equal to the ratio between horizontal-polarized and vertical- polarized brightness temperatures of sea surface with nearly 100\% ice concentration, as shown as the slope of straight line $\mathrm{AD}$ in Figure 1(a).

However, for all area in Arctic Ocean, the ratio $\alpha$ cannot be determined by the ratio of dual-polarized brightness temperatures in Equation (4), due to the less sea ice concentration and influence from sea water on brightness temperature in Equation (2). The spatial distribution of $\alpha$ is shown in Figure 1(b). The ratio is relatively small (less than 0.73 ) with sparse contours in open water. The ratio clearly changes at the marginal ice zone (MIZ) from 0.73 to 0.92 and the contours become denser. In the regions covered with sea ice, the most of $\alpha$

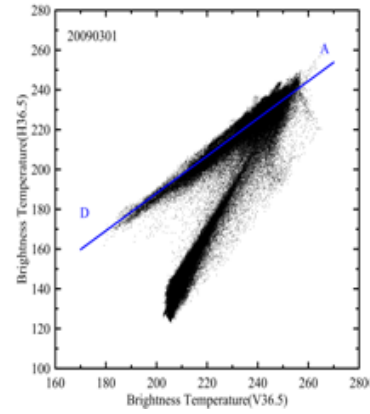

(a)

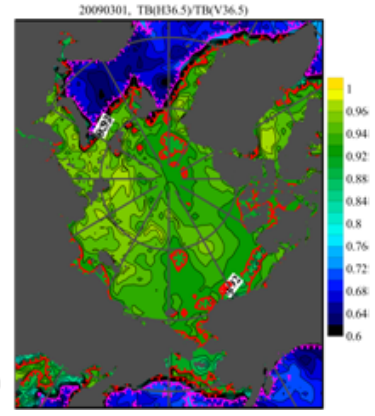

(b)

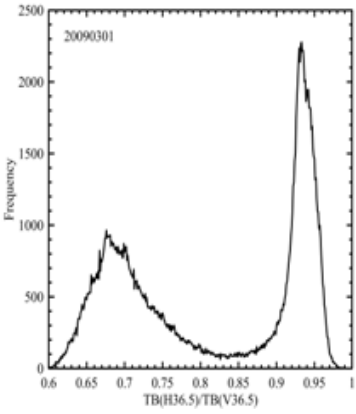

(c)

Figure 1. (a) Scatter plot of HV36.5GHz (Note, the slope of line AD is 0.94); (b) Spatial distribution of the ratio about $\mathrm{H} 36.5$ and $\mathrm{V} 36.5 \mathrm{GHz}$; $\mathrm{c}$ histogram of the ratio about $\mathrm{H} 36.5$ and $\mathrm{V} 36.5 \mathrm{GHz}$. 
values change from 0.92 to 0.96 and the contours are also very sparse. Figure 1(b) also indicates that there is no difference between multiyear ice and first year ice for $\alpha$. Because of mixing of the sea ice and seawater, the $\alpha$ change is very large. So there should be a threshold ratio $\alpha_{0}$ at ice margins: When $\alpha$ is larger than $\alpha_{0}$, the $\alpha$ is mainly affected by sea ice and dual-polarized brightness temperature data distribute along a straight line; otherwise the $\alpha$ is significantly influenced by sea water. Therefore, $\alpha_{0}$ is the threshold ratio used to distinguish the ice margins.

Figure 1(c) shows the frequency histogram of $\alpha$ (from 0.600 to 0.970 ) for the whole Arctic region, the interval is 0.001 . Two peaks appear: the left one corresponds to open water, and the right one corresponds to the sea surface with high sea ice concentration. In the sea ice covered regions, the value of $\alpha$ is limited from 0.92 to 0.96 as shown in Figure 1(b), but the frequency of $\alpha$ with the values between 0.92 and 0.96 exhibits obvious change as shown in Figure $1(c)$.

\subsection{Definition of Contrast Ratio}

There is no apparent boundary at ice margins because sea ice concentration is gradually changing from open water to ice margins. In this section, a new parameter, called as the contrast ratio, is used to quantitatively calculate the threshold ratio $\alpha_{0}$. Contrast ratio full use of the gradient of pixel and the number of pixel to outstanding ice margins [21]. First, the frequency $\omega(\alpha)$ of each $\alpha$ from 0.600 to 0.970 is calculated for the whole Arctic region, as shown in Figure 1(c). Second, the difference of $\alpha$ between each grid and its neighboring grids needs to be calculated. If the difference is larger than a threshold value $p$, the frequency $\delta(\alpha)$ is calculated. Here $\delta(\alpha)$ denotes the frequency of $\alpha$ with the difference larger than threshold value $p$. Finally, the contrast ratio $\lambda(\alpha)$ is defined as

$$
\lambda(\alpha)=\delta(\alpha) / \omega(\alpha)
$$

The definition of $\lambda(\alpha)$ includes two important information about $\alpha$ : the change in the value of $\alpha$ and the change in its frequency. Therefore, $\lambda(\alpha)$ can represent the features of $\alpha_{0}$ at the ice margins.

The threshold value $p$ can be chosen arbitrarily according to $\alpha$, because it only changes the value of $\lambda(\alpha)$ but it does not alter the curve shape of the contrast ratio. In this paper, 0.005 is chosen as threshold value $p$. In some grids, $\alpha$ is higher than the threshold value $p$ in several neighboring grids; so $\lambda(\alpha)$ could be larger than 1 . The gradient of $\lambda(\alpha)$ can quantitatively describe the change of $\lambda(\alpha)$ and can be written as

$$
X(\alpha)=\partial[\lambda(\alpha)] / \partial \alpha
$$

The contrast ratio $\lambda(\alpha)$ (black line) and its gradient (red line) are shown in Figure 2(a). Here Contrast ratio $\lambda(\alpha)$ decreases rapidly from 1.4 to less than 0.5 for $\alpha$ values between 0.90 and 0.93 , while the most abrupt changes occur at 0.92 . Thus, when the ratio $\alpha$ of dual-polarized brightness temperatures is 


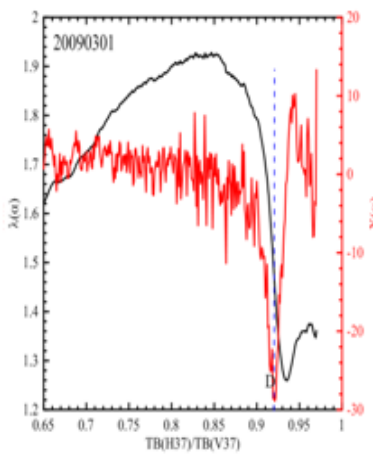

(a)

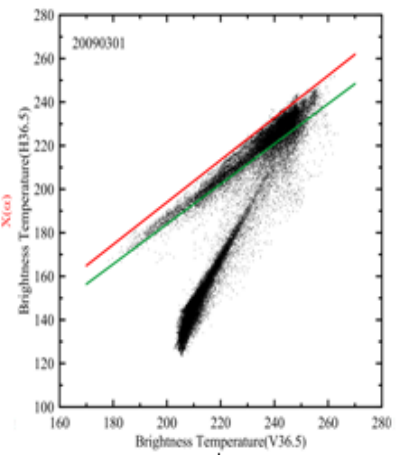

(b)

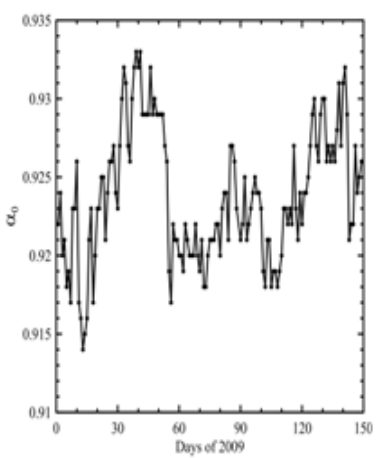

(c)

Figure 2. (a) Contrast ratio $\lambda(\alpha)$ (black) and its gradient $X(\alpha)$ (red); (b) Scatter plot of $\mathrm{HV} 36.5 \mathrm{GHz}$ (Note, the slope of green line is 0.92, red line is 0.97); (c) Time series of threshold ratio $\alpha_{0}$ before June, 2009.

equal to 0.92 , the dual-polarized emissivity ratio reaches its threshold ratio of $\alpha_{0}$. In Figure 2(b), two zero-crossing lines are shown in scatter plot. The slope of green line is 0.92 and the slope of red line is 0.97. It is apparent that the data points linearly distribute between the green line and red line when the $\alpha$ is larger than 0.92 . So the value of $\alpha_{0}$ can be derived using $\lambda(\alpha)$ and $X(\alpha)$, as shown in Figure 2(c). The value of $\alpha_{0}$ before June showed relative stability, fluctuating mainly between 0.92 and 0.93 .

\section{Validation and Discussion}

\subsection{Validation}

The threshold ratio $\alpha_{0}$ is determined using contrast ratio of brightness temperature in Section 2 and its value changed around 0.92 before June. In order to verify that $\alpha_{0} \approx 0.92$ is correct, we will compare the positions of sea ice margin, obtained from microwave image and MODIS images, respectively. MODIS images could be used to verify the position of sea ice edge, sea ice concentration and sea ice leads [19] [16]. Band 2 of the MODIS sensor (841 - $876 \mathrm{~nm}$ ) has a spatial resolution of $250 \mathrm{~m}$. So MODIS image of band 2 could be used to validate the ice margins. For validation, the chosen MODIS images must be those observed in very clear days to eliminate the influence of clouds.

Zhao and Ren [21] determined the threshold between the sea ice and sea water in the aerial image using contrast ratio. Then sea ice edge, sea ice concentration and sea ice size are studied in aerial image. So this method can also used in the MODIS images to discriminate ice and water because of their highly contrasted albedo. Figure 3 show four images of MODIS at spring of 2009 (Top pictures), their discriminated pictures (Middle pictures) and corresponding sea ice concentration pictures (Bottom pictures). White and black pixels in the middle pictures represent sea ice and sea water, respectively.

The pixels of bottom pictures of Figure 3 are $12.5 \times 12.5 \mathrm{~km}$, which is composed of 2,500 MODIS pixels, so sea ice concentration are the percentage of ice pixels among the 2,500 MODIS pixels. The white contour demotes the pixel with 


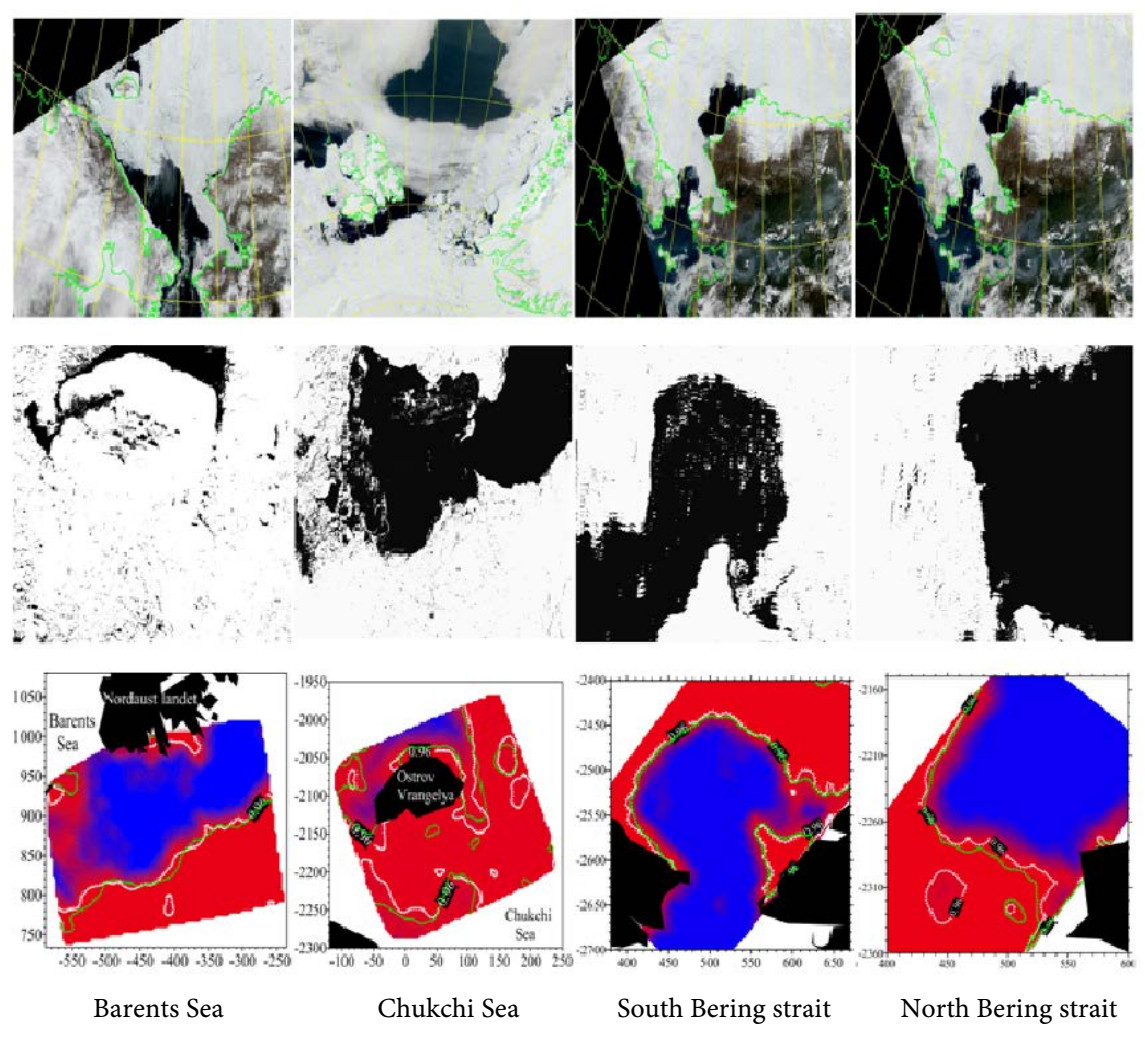

Figure 3. MODIS images, top pictures; Ice-water discriminated pictures, middle pictures; sea ice concentration retrieved by MODIS images, bottom. NOTE: The MODIS images down load from http://ladsweb.nascom.nasa.gov/.

96\% sea ice concentration and the green contour denotes the pixel in which the ratio $\alpha$ is equal to 0.92 . In the Section 2, we know that the threshold ratio $\alpha_{0}$ fluctuates mostly between 0.92 and 0.93 . Calculation indicated that an average sea ice concentration corresponding to $\alpha_{0}$ is 0.96 . The Figure 3 shows that the red contour is very closed to green contour and their shape is very similar to each other.

Table 1 lists the average curve separation (ACS), mean absolute difference (MSD), and root mean square error (RMS) between the red contour and green contour in the four regions of Figure 3. The maximum of ACS, MSD and RMS is $10.5 \mathrm{~km}, 10.0 \mathrm{~km}, 6.5 \mathrm{~km}$, respectively, which are well lower than the size of AMSR-E grid $(12.5 \mathrm{~km})$. Figure 4 shows the distance histograms of these four ice margins and shows that the majority of the distances are less than $12.5 \mathrm{~km}$.

Figure 3 and Figure 4 indicate that the distance between red contour and green contour is relatively small in the ocean, except few regions with distance larger than $12.5 \mathrm{~km}$. This phenomenon is caused mainly by three reasons. Firstly, cloud could not be distinguished from sea ice in the MODIS image. Secondly, the melted pond and sea water cannot be distinguished in microwave image. Finally, the MODIS shows the image at a moment, however; AMSR-E shows the brightness temperature at another moment. In addition, the movement of sea ice may cause the difference between MODIS and AMSR-E in sea ice margins. 


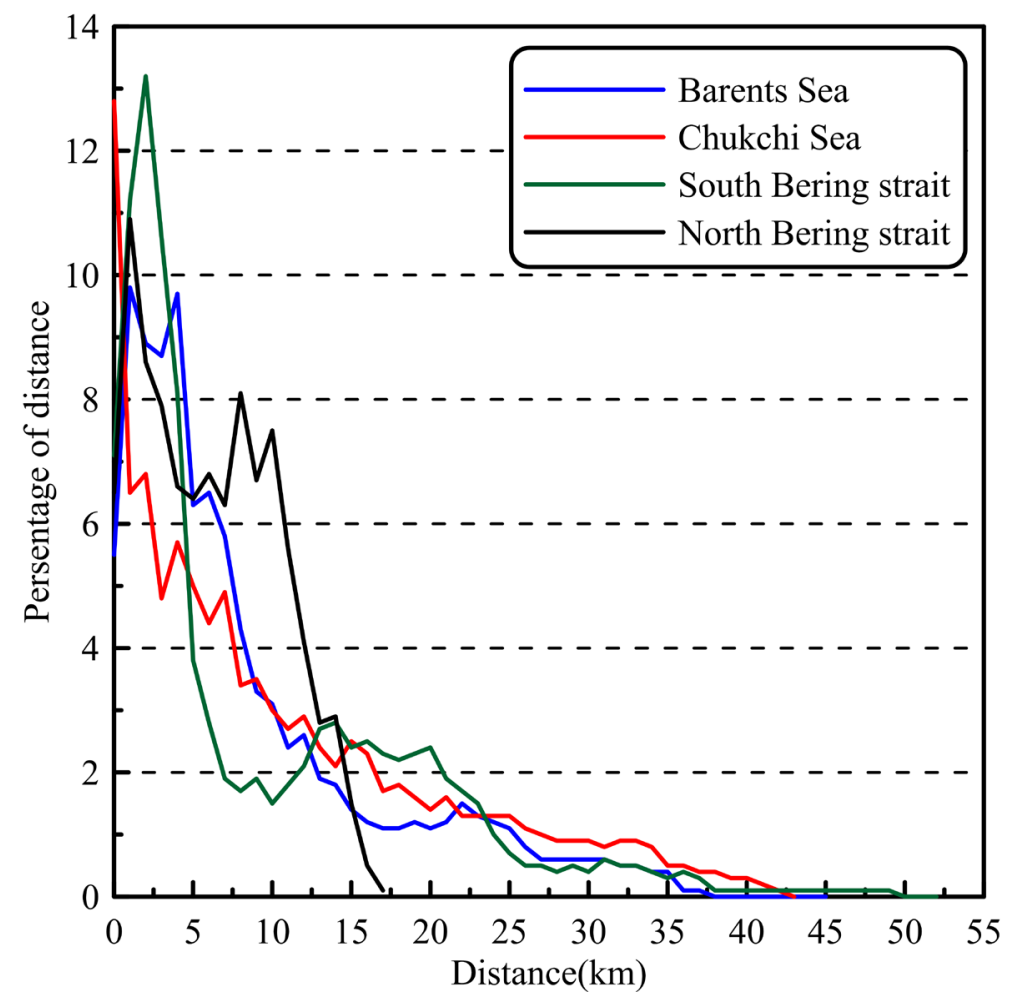

Figure 4. Histograms of distances between ice margins derived from AMSR-E and MODIS.

Table 1. Statistical analysis of sea ice margins derived from AMSR-E and MODIS. ACS is average curve separation, MSD is mean absolute difference and RMS is root mean square.

\begin{tabular}{cccc}
\hline Position & ACS $(\mathrm{km})$ & MSD $(\mathrm{km})$ & RMS $(\mathrm{km})$ \\
\hline Barents Sea & 8.6 & 6.4 & 8.3 \\
Chukchi sea & 10.5 & 10.0 & 8.2 \\
South Bering strait & 6.2 & 3.6 & 4.2 \\
North Bering strait & 9.2 & 7.8 & 9.5 \\
\hline
\end{tabular}

\subsection{Discussion}

A method for determining the ice margins is given in this paper. The threshold ratio $\alpha_{0}$ can be used to distinguish the ice margins. Here $\alpha_{0}$ is the dual-polarized emissivity ratio at $36.5 \mathrm{GHz}$ in the sea ice coverage area. When sea ice concentration is close to 1 , the dual-polarized brightness temperatures can be plotted along a line that crosses the origin of coordinates in the scatter plot, as shown in Figure 1(a). At the same time, the ratio of dual-polarized brightness temperatures is unaffected by the type of sea ice and its value changes mostly from 0.92 to 0.96 in the sea ice coverage area. However, under the influence of sea water, a rapid change of $\alpha$ occurs from open water to sea ice margins. All these characteristics can be used to determine a threshold ratio $\alpha_{0}$, which defines margins of high sea ice concentration coverage. The contrast ratio of dual-polarized brightness temperature is used to determine the $\alpha_{0}$. The study 
found that the $\alpha_{0}$ changes around 0.92 and the data of dual-polarized brightness temperatures distribute along a straight line in scatter plot when $\alpha$ is larger than $\alpha_{0}$.

The position of the ice margins not only is a principal feature in microwave image, but also has an important significance in sea ice concentration retrieving. Sea ice concentration retrieved from passive microwave data over the high concentration Arctic sea ice has shown biases which are about one magnitude larger than the true variability [22]. In the same sea ice concentration algorithm, using different parameters may lead to larger differences of the sea ice concentration. For example, the Bootstrap Algorithm can be used to calculate the sea ice concentration once the line $\mathrm{AD}$ is determined in Figure 1(a). The slope of the line $\mathrm{AD}$ is 1.00 or 1.04 in the Bootstrap Algorithm, and the line AD does not cross the origin of the coordinates. However, in this paper, not only the line $\mathrm{AD}$ crosses the origin but also its slope changes between 0.92 and 0.96 . So it is very important that the position of the ice margins need to be verified in sea ice concentration algorithm according to the features of dual-polarized brightness temperature at $36.5 \mathrm{GHz}$.

The ice margins are determined not only by sea ice concentration, which are retrieved by brightness temperature, but also by the ratio of dual-polarized brightness temperatures at $36.5 \mathrm{GHz}$. One of the advantages is that new method avoids the impact of error of sea ice concentration retrieval. Validation results indicate that this new method can be used to determine the ice margins of passive microwave imagery. So this method has a good practical and applied value.

\section{Conclusions}

The Arctic is undergoing rapid change, such as sea ice extent decreases and sea ice concentration decline in recent years. These results leaded that marginal ice zone (MIZ) greatly expanded and MIZ became an important climatic factor in the study on ocean-atmosphere interactions. The position of ice margins is very important in studying MIZ. A method for determining the ice margins is developed using the features of dual-polarized brightness temperatures at $36.5 \mathrm{GHz}$ and a new parameter (contrast ratio) is used in the method. The specific conclusions are given as follows:

(1) The data of dual-polarized brightness temperature at $36.5 \mathrm{GHz}$ distribute along a straight line in scatter plot, which are corresponding to nearly $100 \%$ sea ice concentration in Arctic, and the line crosses the origin of the coordinates. The slope of the line is equal to the ratio of horizontal emissivity to vertical emissivity of ice and its value changes between 0.92 and 0.96 .

(2) From open water to sea ice covered area, the parameter of contrast-ratio can show the changing features of the ratio of dual-polarized brightness temperature at $36.5 \mathrm{GHz}$. At the influence of sea water, the contrast ratio rapidly changes at the high sea ice concentration margins and its gradient appears extreme value when the ratio of dual-polarized brightness temperature changes around 0.92 . In the scatter plot, the data of dual-polarized brightness tempera- 
ture at $36.5 \mathrm{GHz}$ apparently distribute along a straight line in scatter plot when their ratio larger than 0.92 . Therefore, the threshold value is 0.92 which determine the ice margins in Arctic Ocean.

\section{Acknowledgements}

The authors gratefully acknowledge the support for this work under the National Natural Science Foundation of China (41406208), the Scientific and Youth Science Funds of Shandong Academy of Sciences, China (2013QN042), the Open Research Fund of the State Oceanic Administration of the People's Republic of China Key Laboratory for Polar Science (3KP201203). We also acknowledge AMSR-E data and MODIS image provided by the National Snow and Ice Data Center and NASA.

\section{References}

[1] Lindsay, R. and Schweiger, A. (2015) Arctic Sea Ice Thickness Loss Determined Using Subsurface, Aircraft, and Satellite Observations. Cryosphere, 9, 269-283. https://doi.org/10.5194/tc-9-269-2015

[2] Boisvert, L.N. and Stroeve, J.C. (2015) The Arctic Is Becoming Warmer and Wetter as Revealed by the Atmospheric Infrared Sounder. Geophys. Res. Lett., 42, 4439-4446. https://doi.org/10.1002/2015GL063775

[3] Stroeve, J.C., Crawford, A.D. and Stammerjohn, S. (2016) Using Timing of Ice Retreat to Predict Timing of Fall Freeze-Up in the Arctic. Geophys. Res. Lett., 43, 6332-6340. https://doi.org/10.1002/2016GL069314

[4] Overland, J.E., Francis, J.A. and Wang, M. (2012) The Recent Shift in Early Summer Arctic Atmospheric Circulation. Geophys. Res. Lett., 39.

https://doi.org/10.1029/2012gl053268

[5] Serreze, M.C., Barrett, A.P., Stroeve, J.C., Kindig, D.N. and Holland M.M. (2009) The Emergence of Surface-Based Arctic Amplification. Cryosphere, 3, 11-19. https://doi.org/10.5194/tc-3-11-2009

[6] Close, S., Houssais, M.N. and Herbaut, C. (2015) Regional Dependence in the Timing of Onset of Rapid Decline in Arctic Sea Ice Concentration. J. Geophys. Res. Oceans, 120, 8077-8098. https://doi.org/10.1002/2015JC011187

[7] Casey, J.A., Howell, E.L., Tivy, A. and Haas, C. (2016) Separability of Sea Ice Types from Wide Swath C- and L-Band Synthetic Aperture Radar Imagery Acquired During the Melt Season. Remote Sensing of Environment, 174, 314-328. https://doi.org/10.1016/j.rse.2015.12.021

[8] Kirtman, B., et al. (2013). Near-Term Climate Change: Projections and Predictablility, in Climate Change 2013: The Physical Science Basis. Contribution of Working Group 1 to the Fifth Assessment Report of the Intergovernmental Panel on Climate Change. Cambridge Univ. Press, Cambridge.

[9] Webster, M.A., Rigor, I.G., Perovich, D.K., Rechter-Menge, J.A., Polashenski, C.M. and Light, B. (2015) Seasonal Evolution of Melt Ponds on Arctic Sea Ice. J. Geophys. Res. Oceans, 120, 5968-5982. https://doi.org/10.1002/2015JC011030

[10] Sumata, H., Kwok, R., Gerdes, R., Kauker, F. and Karcher M. (2015) Uncertainty of Arctic Summer Ice Drift Assessed by High-Resolution SAR Data. J. Geophys. Res. Oceans, 120, 5285-5301. https://doi.org/10.1002/2015JC010810

[11] Cavalieri, D.J., Gloersen, P. and Campbell, W.J. (1984) Determination of Sea Ice 
Parameters with the NIMBUS 7 SMMR. J. Geophys. Res., 89, 5355-5369. https://doi.org/10.1029/JD089iD04p05355

[12] Key, J.R., Mahoney, R., Liu, Y., Romanov, P., et al. (2013) Snow and Ice Products from Suomi Npp VIRS. J. Geophys. Res. Atmos., 118, 12816-12830.

https://doi.org/10.1002/2013/D020459

[13] Comiso, J.C., Cavalieri, D.J. and Markus, T. (2003) Sea Ice Concentration, Ice Temperature, and Snow Depth Using AMSR-E Data. IEEE Trans. Geoscience and Remote Sensing, 41, 243-252. https://doi.org/10.1109/TGRS.2002.808317

[14] Peng, G., Meier, W.M., Scott, D.J. and Savoie, M.H. (2013) A Long-Term and Reproducible Passive Microwave Sea Ice Concentration Data Record for Climate Studies and Monitoring. Earth Syst. Sci. Data, 5, 311-318.

https://doi.org/10.5194/essd-5-311-2013

[15] Spreen, G., Kaleschke, L. and Heygster, G. (2008) Sea Ice Remote Sensing Using AMSR-E $89 \mathrm{GHz}$ Channels. J.Geophys. Res., 113.

https://doi.org/10.1029/2005jc003384

[16] Zhang, S.G., Zhao, J.P., Frey, K. and Su, J. (2013) Dual-Polarized Ratio Algorithm for Retrieving Arctic Sea Ice Concentration from Passive Microwave Brightness Temperature. Journal of Oceanography, 69, 215-227. https://doi.org/10.1007/s10872-012-0167-z

[17] Heinrichs, J.F., Cavalieri, D.J. and Markus, T. (2006) Assessment of the AMSR-E Sea Ice Concentration Product at the Ice Edge Using RADARSAT-1 and MODIS Imagery. IEEE Trans. Geosci. Remote Sens., 44, 3070-3080. https://doi.org/10.1109/TGRS.2006.880622

[18] Comiso, J.C. and Nishio, F. (2008) Trends in the Sea Ice Cover Using Enhanced and Compatible AMSR-E, SSM/I, and SMMR data. J. Geophys. Res. 113. https://doi.org/10.1029/2007jc004257

[19] Röhrs, J. and Kaleschke, J. (2010) An Algorithm to Detect Sea Ice Leads Using AMSR-E Passive Microwave Imagery. The Cryosphere Discuss., 4, 183-206. https://doi.org/10.5194/tcd-4-183-2010

[20] Grenfell, T. and Lohanick, A.W. (1985) Temporal Variations of the Microwave Signatures of Sea Ice During the Late Spring and Early Summer Near Mould Bay, NWT. J. Geophys. Res., 90, 5063-5074. https://doi.org/10.1029/jc090ic03p05063

[21] Zhao, J.P. and Ren, J.P. (2000) From Airlines Digital Image Extraction Method of Arctic Sea Ice Form Parameters. Journal of Remote Sensing, 4, 271-278.

[22] Andersen, S., Tonboe, R., Kaleschke, L., Heygster, G. and Pedersen, L.T. (2007) Intercomparison of Passive Microwave Sea Ice Concentration Retrievals over the High-Concentration Arctic Sea Ice. J. Geophys. Res. 112. https://doi.org/10.1029/2006jc003543 